\title{
Microstructural Effect of Magnetic Properties of FeCo-based Soft Magnetic Alloys
}

\author{
R. H. Yu, S. Basu, Y. F. Li, Y. Zhang, G. C. Hadjipanayis, B. E. Lorenz*, and John Q. Xiao \\ Department of Physics and Astronomy, University of Delaware, Newark, DE 19716 \\ *School of Engineering, Widener University, Chester, PA 19013
}

(Received; May 6, 1998 Accepted; August 26, 1998)

\begin{abstract}
We have systematically investigated the effect of microstructure on the magnetic properties of $\mathrm{Fe}_{\mathrm{bal}} \mathrm{Co}_{49} \mathrm{~V}_{1.9}$, $\mathrm{Fe}_{\text {bal }} \mathrm{Co}_{49} \mathrm{~V}_{1.9} \mathrm{Nb}_{0.3}, \quad \mathrm{Fe}_{\mathrm{bal}} \mathrm{Co}_{27} \mathrm{Cr}_{0.6} \mathrm{Ni}_{0.6}, \quad \mathrm{Fe}_{\mathrm{bal}} \mathrm{Co}_{27} \mathrm{Cr}_{0.6^{-}}$ $\mathrm{Ni}_{0.6} \mathrm{C}_{0.3}$ alloys in a temperature range of $20-700{ }^{\circ} \mathrm{C}$. The effects of microstructure, the grain size, second phase precipitation, density of dislocation, and structural ordering parameter have been separated each other and been determined. The second phase precipitation which appears in high temperature aged samples causes the magnetic properties to deteriorate significantly. The increase of the structural ordering parameter, which was determined by neutron diffraction, improves the magnetic properties. The grain size mainly affects the coercivity field.
\end{abstract}

Key Words: magnetization, Coercivity, microstructure, ordering parameter, grain size, second phase, precipitation, soft magnetic materials, aging, FeCo alloy.

\section{Introduction}

Body-centered cubic (bcc) $\mathrm{Co}_{x} \mathrm{Fe}_{100-\mathrm{x}}$ alloys with $\mathrm{x}=27$ and 50 are probably the most promising soft magnetic materials for high temperature applications such as turbine engines and electric vehicles. The phase diagram of Fe-Co is rather complicated and is still being refined ${ }^{1)}$. In the range of 30 to 70 at.\% $\mathrm{Co}, \mathrm{FeCo}$ alloys undergo a phase transition from a chemically disordered phase (space group $\mathrm{Im} 3 \mathrm{~m})$ to an ordered phase $(\mathrm{Pm} 3 \mathrm{~m})$ below $730^{\circ} \mathrm{C}$. The ordered alloys are magnetically soft and exhibit large magnetic permeabilities ${ }^{2)}$. This magnetic softness is attributed to low magnetic anisotropy constant $\mathrm{K}_{1}$ which crosses zero at $x \approx 50$. The alloy with $x \approx 27$ always shows a disordered bcc structure which is insensitive to the heattreatment below $900{ }^{\circ} \mathrm{C}{ }^{3}$. The addition of a third element, such as $\mathrm{V}$ and $\mathrm{Cr}$, significantly improves the ductility of the ordered phase, but causes the magnetic properties to deteriorate. Especially during high temperature aging or slow cooling after heat-treatment, the inclusion of third elements will lead to the precipitation of second phases ${ }^{4)}$. The appearance of those second phases adversely affects the soft magnetic properties of FeCo alloys.

It is well established that microstructural factors, such as grain size ${ }^{5)}$, dislocation ${ }^{6)}$, precipitation ${ }^{5)}$, and chemically ordering parameter ${ }^{7)}$, significantly affect the magnetic properties of bulk soft magnetic alloys. However, a clear understanding of magnetic properties of FeCo alloys associated with microstructure is still absent. In this work, we have investigated the magnetic properties of $\mathrm{FeCo}$ alloys up to $730^{\circ} \mathrm{C}$ and related microstructural change. An attempt was made to separate and identify the relationship between individual microstructural factors and magnetic properties.

\section{Experiments}

FeCo alloys of norminal compositions of $\mathrm{CO}_{49} \mathrm{~V}_{1.9} \mathrm{Fe}_{\mathrm{bal}}$, $\mathrm{Co}_{49} \mathrm{~V}_{1.9} \mathrm{Nb}_{0.3} \mathrm{Fe}_{\text {bal }}, \quad \mathrm{Co}_{27} \mathrm{Cr}_{0.6} \mathrm{Ni}_{0.6} \mathrm{Fe}_{\text {bal }}$, and $\mathrm{Co}_{27} \mathrm{Cr}_{0.6}$ $\mathrm{Ni}_{0.6} \mathrm{C}_{0.3} \mathrm{Fe}_{\text {bal }}$ were obtained from Carpenter Technology, Inc. The rolled $0.25 \mathrm{~mm}$ thin sheets were machined into different size and shape samples before heat-treatment. The samples were heat-treated at high temperature in a flowing $\mathrm{H}_{2}$ atmosphere in order to obtain a desired structure. Toroidal samples were used to measure the magnetic properties. Prior to the measurements, the oxidized layers were removed by diluted acid solution. The magnetic properties were measured with a hysteresis loop tracer. The grain size was determined by an optical microscope using the etched FeCo samples. The density of dislocation and precipitation of second phase were characterized by TEM analyses. The long range order parameter $S$ was determined using neutron diffraction technique. Superlattice peaks were clearly observed using neutron radiation, for which the difference of structural scattering factors $\left(\mathrm{f}_{\mathrm{Fe}}-\mathrm{f}_{\mathrm{CO}_{\mathrm{O}}}\right)$ is maximized. The ordering parameter was computed from the ratio of integrated intensities $\mathrm{I}_{100} / \mathrm{I}_{200}$.

\section{Results and discussions}

FeCo alloys show very poor mechanical properties, especially in the ordered state. Third elements such as V are usually added to improves their mechanical strength as well as ductility. Table 1 shows $\mathrm{DC}$ magnetic and $\mathrm{AC}$ properties at frequency $\mathrm{f}=400 \mathrm{~Hz}$ for alloys with additions of $\mathrm{V}, \mathrm{Ni}, \mathrm{Cr}$, and $\mathrm{C}$. It can be seen that the inclusions of those elements degrade DC soft magnetic properties, i.e. increase the coercivity and decrease the magnetization. Experiments also indicate that the additives may lead to the formation of second phase without significantly changing the microstructure which depends on the addition content. Following, we will focus on the microstructural effect of magnetic properties induced by heat-treatment.

Figure 1 shows the chemical ordering parameter dependence of magnetization $M$ and coerctvity $H_{c}$ for $\mathrm{Co}_{49} \mathrm{~V}_{1.9} \mathrm{Fe}_{\text {bal }}$ alloy. As stated before ${ }^{1)}$, the stable phase above $730^{\circ} \mathrm{C}$ is bcc disordered structure. This disordered phase can be frozen to room temperature through fast quenching or transformed to ordered phase by slowly cooling the sample to room temperature. By changing the cooling rate, samples with different long range order parameters can be readily obtained as shown in Fig.1. An increase of saturation magnetization on ordering is 
currently under theoretical study. The increase of coercivity with decreasing the order parameter may be due to two factors: high density of dislocation introduced through fast quenching and the random arrangement of the atoms in lattice. The former has been confirmed using
TEM observations. The latter will change the magnetocrystalline anisotropy $\mathrm{K}_{1}$. Previous study ${ }^{8)}$ has shown that $K_{1}$ is slightly lower in the ordered state than that in the disordered state. Both of those factors are believed to increase the coercivity field.

Table 1. Magnetic properties of four alloys annealed at $820^{\circ} \mathrm{C}+2 \mathrm{~h}$, then cooled at $90 \mathrm{oC} / \mathrm{h}$ to room temperature.

\begin{tabular}{|c|c|c|c|c|c|c|}
\hline & \multicolumn{4}{|c|}{$(\mathrm{H}=80 \mathrm{Oe})$} & \multirow{2}{*}{\multicolumn{2}{|c|}{$\begin{array}{c}\begin{array}{c}\text { Core Loss } \\
(\mathrm{W} / \mathrm{kg})\end{array} \\
(\mathrm{f}=400 \mathrm{~Hz})\end{array}$}} \\
\hline & \multicolumn{2}{|c|}{$\mathrm{DC}$} & \multicolumn{2}{|c|}{$\mathrm{AC}(\mathrm{f}=400 \mathrm{~Hz})$} & & \\
\hline & $\mathbf{M}(\mathrm{kG})$ & $\mathrm{Hc}(\mathrm{Oe})$ & $\mathrm{M}(\mathrm{kG})$ & $\mathrm{Hc}(\mathrm{Oe})$ & RT & $600^{\circ} \mathrm{C}$ \\
\hline $\mathrm{Fe}_{\mathrm{hal}} \mathrm{Co}_{49} \mathrm{~V}_{1.9}$ & 23.7 & 1.7 & 21.6 & 2.3 & 33 & 24 \\
\hline $\mathrm{Fe}_{\mathrm{bal}} \mathrm{Co}_{49} \mathrm{~V}_{1.9} \mathrm{Ni}_{0.3}$ & 22.8 & 2.4 & 20.7 & 3.0 & 48 & 30 \\
\hline $\mathrm{Fe}_{\text {bal }} \mathrm{Co}_{27} \mathrm{Cr}_{0.6} \mathrm{Ni}_{0.6}$ & 21.6 & 2.7 & 17.9 & 3.1 & 72 & 36 \\
\hline $\mathrm{Fe}_{\mathrm{bal}} \mathrm{Co}_{27} \mathrm{Cr}_{06} \mathrm{Ni}_{06} \mathrm{C}_{03}$ & 20.2 & 3.1 & 16.7 & 3.6 & 64 & 53 \\
\hline
\end{tabular}
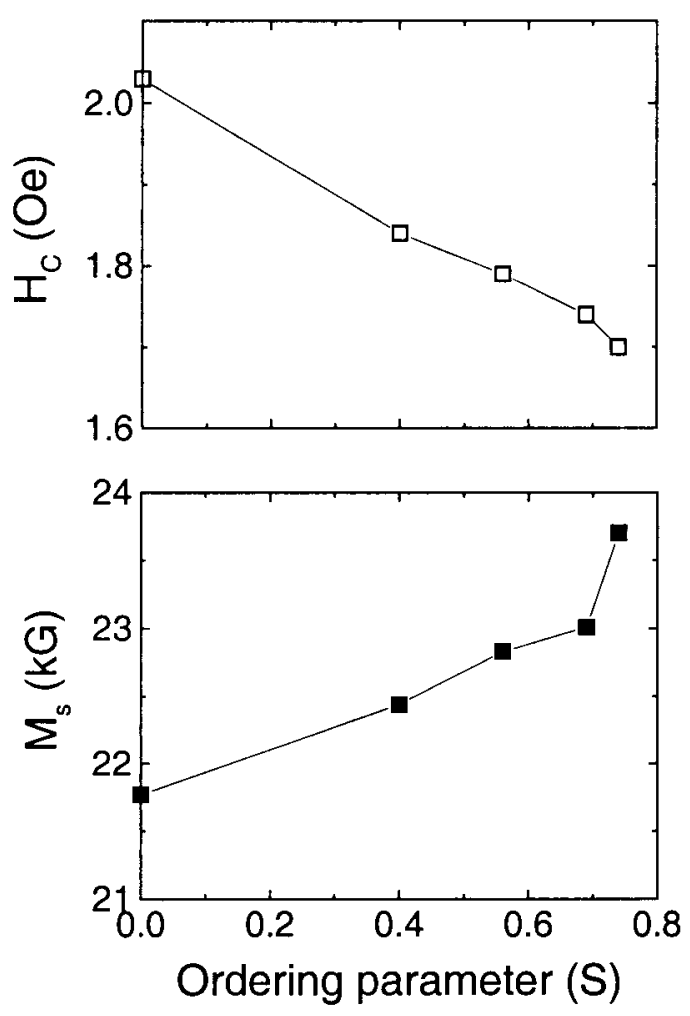

Fig. 1. The coercivity $\mathrm{Hc}$ and saturation magnetization $\mathrm{M}_{\mathrm{s}}$ of Co49V1.9Febal alloys as a function of ordering parameter at room temperature.

We next discuss the effect of grain size on magnetic properties as shown in Fig.2. In order to keep the density of defects and order parameter unchanged, samples were annealed at $820^{\circ} \mathrm{C}$ for different times, then cooled at same rate $\mathrm{R}=90{ }^{\circ} \mathrm{C} / \mathrm{h}$. It is well known that the magnetic properties of soft magnetic alloys are not only determined by magnetic anisotropy but also by distortions in the crystalline structure. The distortions are mainly induced by grain boundaries, defects, second phases, and internal stress. From Fig.2, it is clear that the change of grain size mainly affects the coercivity field, and weakly affects
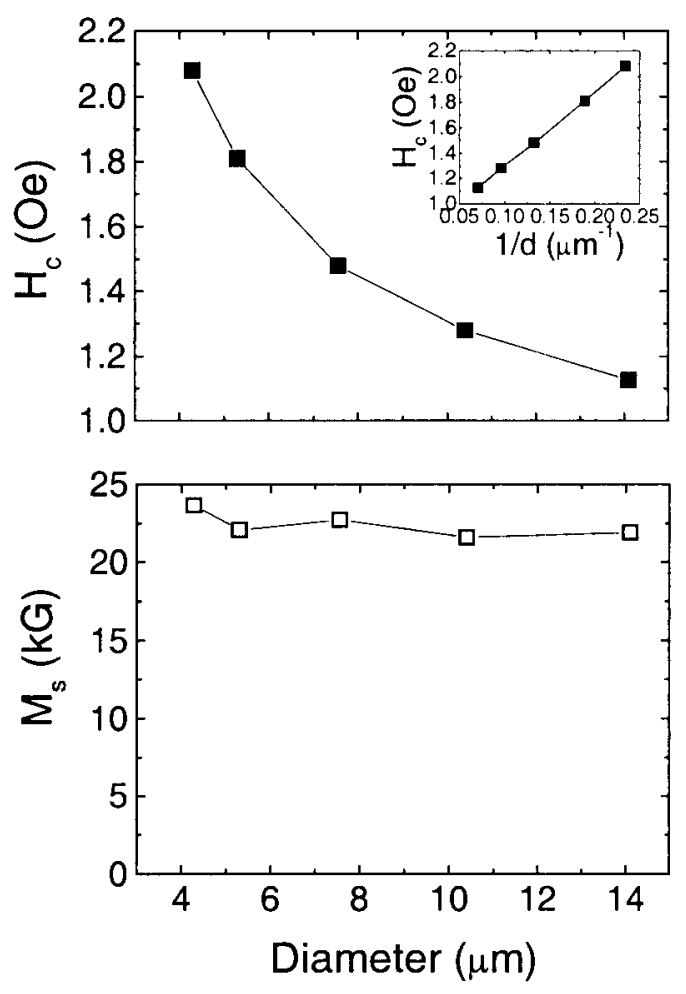

Fig.2. The effect of grain size on the coecivity $\mathrm{H}_{c}$ and saturation magnetization $\mathrm{M}_{\mathrm{s}}$ of $\mathrm{Co}_{49} \mathrm{~V}_{1.9} \mathrm{Fe}_{\text {bal }}$ alloys

the magnetization. According to Mager ${ }^{9)}$, the coercivity field $\mathrm{H}_{\mathrm{c}}$ determined by the grain boundaries is a linear function of the reciprocal grain diameter $1 / d$

$$
H_{C} \approx 3 \frac{\gamma_{w}}{M_{s}} \frac{1}{d}
$$

with the wall energy $\gamma_{w}$ and the saturation magnetization $\mathrm{M}_{\mathrm{s}}$. The wall energy can be estimated using equation:

$$
\gamma_{W} \approx \sqrt{\kappa_{B} T_{C} K_{1} / a}
$$

thus

$$
H_{C} \approx 3 \frac{\sqrt{\kappa_{B} T_{C} K_{1} / a}}{M_{s}} \frac{1}{d}
$$


where $\kappa_{B}$ is Boltzmann constant, $a$ is lattice constant, $K_{1}$ is anisotropy constant, and $T_{c}$ is the Curie temperature. A roughly linear relationship between coercivity field and reciprocal grain diameter is indeed found in our experiments (Fig. 2).
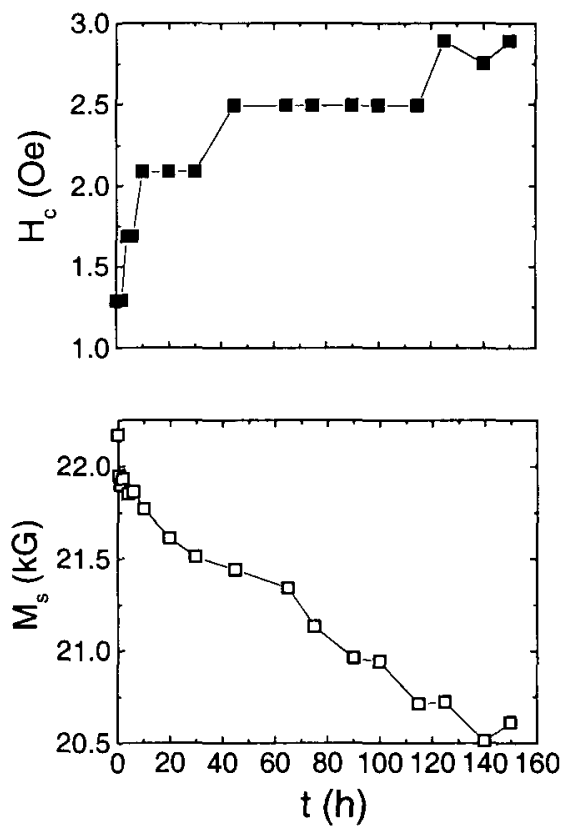

Fig. 3. The change of coercivity $\mathrm{Hc}$ and saturation magnetization $\mathrm{Ms}$ of $\mathrm{Co}_{49} \mathrm{~V}_{1.9} \mathrm{Fe}_{\text {bal }}$ alloys with aging time at $600{ }^{\circ} \mathrm{C}$.

The time effect of aging at $600{ }^{\circ} \mathrm{C}$ on the magnetic properties is shown in Fig. 3. Prior to the aging experiments, the samples were annealed at $820^{\circ} \mathrm{C}$ for $2 \mathrm{~h}$ and cooled at $R=90^{\circ} \mathrm{C} / \mathrm{h}$ to room temperature. The soft magnetic properties deteriorate with increasing aging time. Optical microscopy observation indicates that the grain sizes slightly increase with aging time. Thus, the deterioration of soft magnetic properties was mainly caused by precipitation. This second phase was determined to have L12 structure and is rich in V element. Fig.4 shows a TEM picture illustrating the distribution, size and shape of second phase precipitated in the samples aged for $150 \mathrm{~h}$. This second phase is formed both inside the grain and along the grain boundaries. The influence of second phase on the coercivity field has been treated theoretically in previous works, and most of those works concentrated on the effect of non-magnetic inclusions. For non-magnetic inclusions, Néel [10] predicted that the coercivity field can be approximately expressed as $\mathrm{H}_{c} \propto \mathrm{v}$, where $\mathrm{v}$ is the volume fraction of the non-magnetic inclusions. The second phase formed in $\mathrm{Fe}_{\mathrm{bal}} \mathrm{Co}_{49} \mathrm{~V}_{1.9}$ alloy during the aging process is uncertain in magnetic properties. Therefore, it may not relevant to to use the Néel model to interpret the aging behavior of magnetic properties. A further detailed work will be undertaken soon to clarify the effect of precipitation of second phase on the magnetic properties.

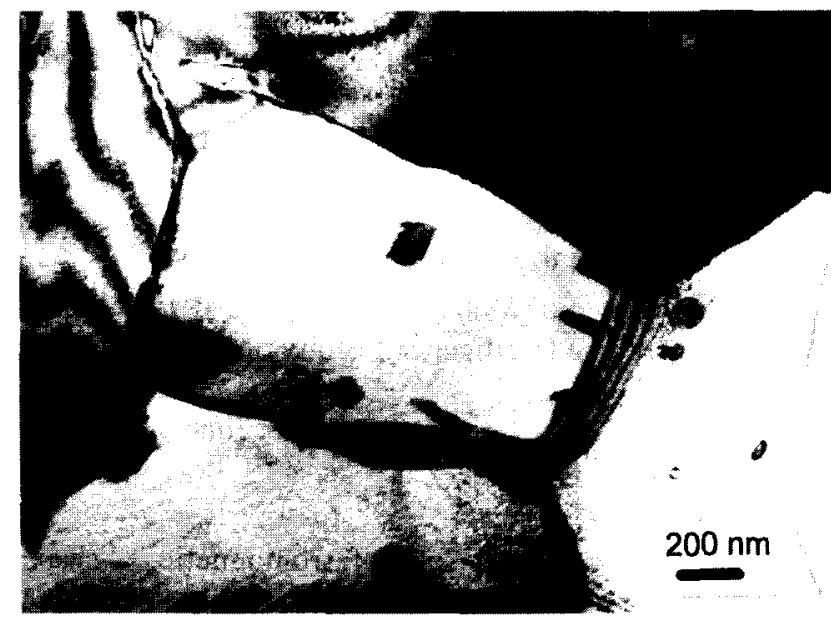

Fig.4. TEM picture for $\mathrm{CO}_{49} \mathrm{~V}_{1.9} \mathrm{Fe}_{\text {bal }}$ alloys aged at 600 ${ }^{\circ} \mathrm{C}$. for $150 \mathrm{~h}$

All the samples with $\mathrm{Co} \approx 50$ at.\% shows similar magnetic behaviors as shown above. For $\mathrm{Co} \approx 27$ at. $\%$, the alloys are always with disordered structure regardless of heat-treatment. But, they follow the same magnetic behaviors associated with second phase and grain size as alloys with $\mathrm{Co} \approx 50$ at. $\%$ behave.

\section{Conclusions}

We have investigated the microstructural effect of magnetic properties of $\mathrm{Co}_{x} \mathrm{Fe}_{100-x}$ alloys with $\mathrm{x}=27$ and 50 . The magnetic moment sensitive structural factors are second phase and ordering parameter. On the other hand, all the structural factors including grain boundaries, ordering parameter, and second phase affect the coercivity field.

Acknowledgements The authors would like to thank Prof. W. B. Yelon and Mr. Mingxing Chen for performing neutron diffraction experiments, and Prof. C. D. Graham for useful discussions. This work is supported by AFOSR MURI F49620-96-1-0434.

\section{References}

1) T. Nishizawa, and K. Ishida, Metal Progr., 57 (1986).

2) R. Boll, Materials Science and Technology, ed. by K. H. Buschow, 1994, Vol. 3B, p. 399 (VCH, Weinheim, 1994).

3) R. H. Yu, S. Basu, G. A. Landry, and J. Q. Xiao, 7-th Joint MMM-INTERMAG Conf., San Francisco, 1998.

4) C. D. Pitt, and R. D. Rawlings, Metal. Sci., 17, 261 (1983).

5) F. Pfeifer, and C. Radeloff, J. Magn. Magn. Mater., 19, $190(1980)$.

6) D. R. Thormberg, J. Appl. Phys., 40, 1579 (1969).

7) T. Muto, and Y. Tatagi, Solid State Physics, Vol. 1, p. 193 (New York, 1955).

8) R. V. Major, and C. M. Orrock, IEEE Trans. On Magn., 24, 1856 (1988).

9) A. Mager, Ann. Phys., 6 F.11, 15 (1952).

10) L. Néel, Ann. Univ. Grenoble, 22, 229 (1946). 